This is the accepted manuscript version of the following article: Živković J, Barreira JCM, Stojković D, Ćebović T, Santos-Buelga C, Maksimović Z, Ferreira ICFR. Phenolic profile, antibacterial, antimutagenic and antitumour evaluation of Veronica urticifolia

Jacq. J Funct Foods. 2014;9(1):192-201.[https://doi.org/10.1016/j.jff.2014.04.024]

(C) 2014 Elsevier Ltd.

(2) $\odot \Theta \Theta$ 


\section{Phenolic profile, antibacterial, antimutagenic and antitumour evaluation of Veronica}

urticifolia Jacq.

Jelena Živković ${ }^{a^{*}}$, João C.M. Barreira, ${ }^{\text {b,c,d }}$, Dejan Stojkoviće ${ }^{\mathrm{e}}$ Tatjana Ćebović ${ }^{\mathrm{f}}$, Celestino Santos-Buelga ${ }^{\mathrm{c},}{ }^{*}$, Zoran Maksimović $^{\mathrm{g}}$, Slobodan Davidović ${ }^{\mathrm{h}}$, Isabel C.F.R. Ferreira ${ }^{\mathrm{b}}$

anstitute for Medicinal Plant Research "Dr. Josif Pančić”, Tadeuša Košćuška 1, 11000 Belgrade, Serbia.

${ }^{\mathrm{b}}$ Mountain Research Centre (CIMO), ESA, Polytechnic Institute of Bragança, Campus de Santa Apolónia, Ap. 1172, 5301-855 Bragança, Portugal.

${ }^{c}$ Grupo de Investigación en Polifenoles (GIP-USAL), Faculty of Pharmacy, University of Salamanca, Campus Miguel de Unamuno, 37007 Salamanca, Spain.

${ }^{\mathrm{d}}$ Chemical Sciences Department, Faculty of Pharmacy, University of Porto, Rua Jorge Viterbo Ferreira, $n^{\circ} 228,4050-313$ Porto, Portugal.

'University of Belgrade, Institute for Biological Research “Siniša Stanković”, Department of Plant Physiology, Bulevar Despota Stefana 142, 11000 Belgrade, Serbia.

${ }^{\mathrm{f}}$ University of Novi Sad, Department of Biochemistry, School of Medicine, Hajduk Veljkova 3, 21102 Novi Sad, Serbia.

${ }^{\mathrm{g}}$ University of Belgrade, Department of Pharmacognosy, School of Pharmacy, University of Belgrade, Vojvode Stepe 450, 11221 Belgrade, Serbia.

${ }^{\mathrm{h}}$ University of Belgrade, Institute of Molecular Genetics and Genetic Engineering, 11010 Belgrade, Serbia.

*Authors to whom correspondence should be addressed: (Jelena Živković; e-mail: jelenazivkovic1@yahoo.com. Phone: +381 648674921; Fax: +381 113031655; Celestino Santos-Buelga; e-mail: csb@usal.es. Phone: +34 923294537; Fax: +34 923294515). 


\begin{abstract}
This study was designed to characterize the phenolic profile and evaluate the antibacterial, antimutagenic and antitumor activities of Veronica urticifolia Jacq. methanolic extract. HPLC-DAD/ESI-MS analysis revealed the presence of phenolic acids, flavonoids and phenylethanoids, with acteoside as the main component (14.9 mg/g of extract). Antibacterial effect was determined using the microbroth dilution assay and Staphylococcus aureus was the most sensitive strain ( $\mathrm{MIC}$ and $\mathrm{MBC}=7.5 \mathrm{mg} / \mathrm{mL}$ ). Antimutagenic activity was evaluated by Ames mutagenicity assay. At $1 \mathrm{mg} /$ plate, the tested extract afforded high protection against the mutagenicity of nitroquinoline-N-oxide (4NQO) to Salmonella typhimurium strain TA100 (inhibition rate 48.3\%). Antitumor activity was screened in Ehrlich ascites carcinoma (EAC) model. Pretreatment with $2 \mathrm{mg} / \mathrm{kg}$ body weight showed statistically significant decrease in tumor cell viability, while ascites volume and tumor cell count became slightly decreased, but not to a statistically significant extent. Above results indicate that $V$. urticifolia deserves further research into chemoprevention.
\end{abstract}

Keywords: Veronica urticifolia; Phenolic profile; HPLC-DAD/ESI-MS; Antibacterial; Antimutagenicity; Ehrlich carcinoma. 


\section{Introduction}

Cancer, the second leading cause of death worldwide next to cardiovascular diseases, is a group of more than 100 different diseases, characterized by uncontrolled cellular growth, local tissue invasion and distant metastases (Madhusudan and Middleton, 2005). According to World Health Organization, more than 10 million new cases of cancer are diagnosed every year, and the statistical trends indicate that this number would double by 2020 (Mignogna et al., 2004). The demand for new anticancer agents is escalating due to the accumulation of carcinogenic and mutagenic agents in the environment. Although many synthetic anticancer agents are used in the treatment of cancer, side effects and emergence of synthetic drug resistant cancer cells among patients limits their purpose (Madhusudan and Middleton, 2005). Recent studies have shown that cancer management by phytochemicals from vegetables, fruits and medicinal plants is one of the most feasible approaches to treat this cascading disease (Dhamija et al., 2013).

In the fight against cancer, the search for antimutagenic agents is essential, since mutagenic and carcinogenic factors are present in the human environment and their total elimination seems to be impossible (Abdillahi et al., 2012). Humans are provided with many defences and their failure could lead to DNA damage and consequently to cancer (El-Sayed and Hussin, 2013). Carcinogenesis is generally a slow process and often takes decades from tumor initiation to diagnosis, offering a considerable time frame for chemopreventive approaches. Chemoprevention is defined as the use of specific natural or synthetic agents to prevent, delay, or slow the carcinogenic process (Martin et al., 2013). The prevention of cancer can be achieved by avoiding exposures to mutagens, by fortifying physiological defence mechanisms, or by supplying the intake of protective factors (De Flora, 1998). Human epidemiology and animal studies have indicated that cancer risk may be modified by changes in dietary habits or by dietary supplements (Miyazawa and Hisama, 2004). 
More than $15 \%$ of malignancies worldwide are established to have an infectious cause (Mager, 2006). Therefore, application of methods to prevent and/or treat infection, such as the use of antimicrobial treatments, could have an effect on future burden of cancer worldwide. Although antibiotics decreased the spread and severity of a wide variety of infectious diseases, bacteria and fungi have developed numerous mechanisms to escape old and new antimicrobial agents due to their uncontrolled use. In this concern, the proper treatment of cancer and microbial infections would have a great impact on the population's health (Assaf et al., 2013).

The identification of dietary components as potential cancer chemopreventive agents in the form of functional foods or as nutraceuticals has become an essential subject of many studies. One of the best approaches in search for anticancer agents from plant resources is the selection of plant species based on ethnomedical leads and testing the selected species efficacy in light of modern science.

In traditional medicine, several Veronica species are used to treat cancer (Harput et al., 2002a). As currently circumscribed, Veronica (Plantaginaceae) is a genus of 450 species found in temperate regions of both hemispheres. Regardless of widespread use, mostly as diuretics, for their wound-healing properties and in medical treatment of respiratory diseases, there is a scarcity of physiological evidence to support any claim of therapeutic values for Veronica species. Only few studies confirm that certain Veronica genus reveal considerable bioactivity such as antibacterial (Stojković et al., 2013; Gusev et al., 2012), antioxidant (Živković et al., 2012), anti-inflammatory (Harput et al., 2002a) and cytotoxic (Harput et al., 2002a; Saracoglu and Harput, 2012) activities.

On the other hand, the phytochemistry of the genus has been extensively studied with many species surveyed for their iridoid (Jensen et al., 2005) and phenylethanoid derivatives 
(Taskova et al., 2006) and flavonoid glycosides (Albach et al., 2003, 2005; Saracoglu et al., 2004; Taskova et al., 2008) with most of these being considered beneficial for human health. Previously we reported in vitro and in vivo antioxidant activity of Veronica urticifolia Jacq. (Živković et al., 2012). Nevertheless, to the best of our knowledge, there are no reports on other biological activities of the selected species. Phenolic profile of the species $V$. urticifoila is presented for the first time. The aim of this study was profiling the phenolic compounds of $V$. urticifolia and evaluating the antibacterial, antimutagenic and antitumor effects of its methanolic extract.

\section{Materials and methods}

\subsection{Plant samples}

The aerial parts of Veronica urticifolia were collected during their flowering period in June 2008 from Mountain Goč in central Serbia. Plant material was taxonomically determined and deposited in the Herbarium collection of the Institute of Botany, School of Pharmacy, Belgrade (voucher specimen numbers were VR 165).

\subsection{Standards and reagents}

HPLC-grade acetonitrile was obtained from Merck KgaA (Darmstadt, Germany). Dimethylsulfoxide (DMSO) (Merck KGaA, Germany) was used as a solvent in antimicrobial assays. Formic acid was purchased from Prolabo (VWR International, France). N-acetyl-Lcysteine and Trypan blue solution were obtained from Sigma-Aldrich (Steinheim, Germany). Nitroquinoline-N-oxide (4NQO) was purchased from Sigma, USA. The phenolic compound standards were from Extrasynthese (Genay, France). Water was treated in a Milli-Q water purification system (TGI Pure Water Systems, USA). 


\subsection{Extraction procedures}

The powdered plant sample $(\sim 1 \mathrm{~g})$ was extracted by stirring with $30 \mathrm{~mL}$ of methanol:water $80: 20(v / v)$, at room temperature, $150 \mathrm{rpm}$, for $1 \mathrm{~h}$. The extract was filtered through Whatman no. 4 paper. The residue was then re-extracted twice with additional portions $(30 \mathrm{~mL})$ of methanol:water 80:20 $(v / v)$. The combined extracts were evaporated at $35{ }^{\circ} \mathrm{C}$ (rotary evaporator Büchi R-210, Flawil, Switzerland) to remove methanol. The aqueous phase was lyophilized and re-dissolved in $20 \%$ aqueous methanol at $5 \mathrm{mg} / \mathrm{mL}$ and filtered through a 0.22- $\mu \mathrm{m}$ disposable LC filter disk for high performance liquid chromatography (HPLC-DADMS) analysis.

For biological activity evaluations, the air dried plant material was reduced to a fine powder and extracted by maceration with methanol in a solid/solvent ratio of 1:20 at room temperature for $48 \mathrm{~h}$. The obtained extract was evaporated under reduced pressure and further kept in a vacuum desiccator to remove traces of solvents.

\subsection{Elucidation of phenolic compounds structures}

The extracts were analysed using a Hewlett-Packard 1100 chromatograph (Agilent Technologies) with a quaternary pump and a diode array detector (DAD) coupled to an HP Chem Station (rev. A.05.04) data-processing station. A Waters Spherisorb S3 ODS-2 $\mathrm{C}_{18}, 3$ $\mu \mathrm{m}(4.6 \mathrm{~mm} \times 150 \mathrm{~mm})$ column thermostatted at $35{ }^{\circ} \mathrm{C}$ was used. The solvents used were: (A) $0.1 \%$ formic acid in water, (B) acetonitrile. The elution gradient established was isocratic $15 \%$ for $5 \mathrm{~min}, 15 \% \mathrm{~B}$ to $20 \% \mathrm{~B}$ over $5 \mathrm{~min}, 20-25 \% \mathrm{~B}$ over $10 \mathrm{~min}, 25-35 \%$ B over $10 \mathrm{~min}$, $35-50 \%$ for $10 \mathrm{~min}$, and re-equilibration of the column, using a flow rate of $0.5 \mathrm{~mL} / \mathrm{min}$; the injection volume was $100 \mu \mathrm{L}$. Double online detection was carried out in the DAD using 280 
$\mathrm{nm}$ and $370 \mathrm{~nm}$ as preferred wavelengths and in a mass spectrometer (MS) connected to HPLC system via the DAD cell outlet.

MS detection was performed in an API 3200 Qtrap (Applied Biosystems, Darmstadt, Germany) equipped with an ESI source and a triple quadrupole-ion trap mass analyzer that was controlled by the Analyst 5.1 software. Zero grade air served as the nebulizer gas (30 psi) and turbo gas for solvent drying $\left(400^{\circ} \mathrm{C}, 40 \mathrm{psi}\right)$. Nitrogen served as the curtain (20 psi) and collision gas (medium). The quadrupols were set at unit resolution. The ion spray voltage was set at $-4500 \mathrm{~V}$ in the negative mode. The MS detector was programmed to perform a series of two consecutive modes: enhanced MS (EMS) and enhanced product ion (EPI) analysis. EMS was employed to record full scan spectra to obtain an overview of all of the ions in sample. Settings used were: declustering potential (DP) $-450 \mathrm{~V}$, entrance potential (EP) $-6 \mathrm{~V}$, collision energy (CE) -10 V. Spectra were recorded in negative ion mode between $\mathrm{m} / \mathrm{z} 100$ and 1000 . Analysis in EPI mode was further performed in order to obtain the fragmentation pattern of the parent ion(s) detected in the previous experiment using the following parameters: DP -50 V, EP -6 V, CE -25 V, and collision energy spread (CES) $0 \mathrm{~V}$.

The phenolic compounds present in the samples were characterized according to their UV and mass spectra and retention times compared with commercial standards when available. For the quantitative analysis of phenolic compounds, a calibration curve was obtained (using the UV detector with $\lambda=280 \mathrm{~nm}$ for phenolic acids and $\lambda=370 \mathrm{~nm}$ for flavonoids) by injection of known concentrations $(1-100 \mu \mathrm{g} / \mathrm{mL})$ of different standards compounds: luteolin-7-Oglucoside $\left(\mathrm{y}=80,829 x-21,291 ; R^{2}=0.999\right)$; apigenin-7-O-glucoside $(\mathrm{y}=159.62 x+7.5025$; $\left.R^{2}=0.999\right) ; 5-O$-Caffeoylquinic acid $\left(\mathrm{y}=313.03 x-58.2 ; R^{2}=0.999\right)$; caffeic acid $(\mathrm{y}=$ $\left.611.9 x-4.5733 ; R^{2}=0.999\right) ; p$-coumaric acid $\left(\mathrm{y}=884,6 x+184,49 ; R^{2}=0.999\right)$.

\subsection{Antibacterial activity}




\subsubsection{Microorganisms and culture conditions.}

For the bioassays seven bacterial strains were used, four Gram-positive: Staphylococcus aureus (ATCC 6538), Bacillus cereus (human isolate), Micrococcus flavus (ATCC 10240) and Listeria monocytogenes (NCTC 7973), and three Gram-negative: Pseudomonas aeruginosa (ATCC 27853), Enterococcus faecalis (human isolate) and Escherichia coli (ATCC 35210).

All of the tested microorganisms were obtained from the Department of Plant Physiology, Institute for Biological Research "Siniša Stanković”, Belgrade, University of Belgrade, Serbia. The bacteria were cultured on Mueller-Hinton agar $(\mathrm{MH})$ and cultures were stored at $+4{ }^{\circ} \mathrm{C}$ and subcultured once a month.

\subsubsection{Microdilution method.}

The minimum inhibitory (MIC) and minimum bactericidal (MBC) concentrations were determined by the modified microdilution method (Espinel-Ingroff, 2001). Briefly, fresh overnight culture of bacteria was adjusted to a concentration of $1 \times 10^{5} \mathrm{CFU} / \mathrm{mL}$ by counting the spores in suspension. The inocula were prepared daily and stored at $+4{ }^{\circ} \mathrm{C}$ until use. Dilutions of inocula were cultured on solid medium to verify the absence of contamination and check the validity of the inoculum. Different solvent dilutions of methanolic extract were carried out over the wells containing $100 \mu \mathrm{L}$ of Tryptic Soy Broth (TSB) and afterwards, 10 $\mu \mathrm{L}$ of inoculum was added to all the wells. The microplates were incubated for $24 \mathrm{~h} 1 \quad$ at 37 ${ }^{\circ} \mathrm{C}$. The MIC of the samples was detected following the addition of $40 \mu \mathrm{L}$ of iodonitrotetrazolium chloride (INT) $(0.2 \mathrm{mg} / \mathrm{mL})$ and incubation at $37{ }^{\circ} \mathrm{C}$ for $30 \mathrm{~min}$. $\mathrm{MBC}$ was determined by serial sub-cultivation of $10 \mu \mathrm{L}$ into microplates containing $100 \mu \mathrm{L}$ of TSB. The lowest concentration that shows no growth after this sub-culturing was read as the MBC. 
Streptomycin (Sigma P 7794) $(0.05-3 \mathrm{mg} / \mathrm{mL})$ was used as positive control for bacterial inhibition. A 5\% solution of DMSO in water was used as negative control.

\subsection{Antimutagenicity}

A variation of the Ames test was used to screen for antimutagenic activity of Veronica urticifolia methanolic extract. For this activity, Salmonella typhimurium TA100 (Molecular Toxicology, Inc) without S9 metabolic activation were used due to cost implications. It is also known that these two strains are capable of identifying up to $90 \%$ of the mutagens (Mortelmans and Zeiger, 2000). Here, $500 \mu \mathrm{L}$ of $0.1 \mathrm{M}$ phosphate buffer was added to $50 \mu \mathrm{L}$ of test sample in a test-tube. Fifty microlitres of the nitroquinoline- $N$-oxide (4NQO) in DMSO $(20 \mu \mathrm{g} / \mathrm{mL}$ ) was added to the mixture and then pre-incubated for $3 \mathrm{~min}$ before the addition of $100 \mu \mathrm{L}$ of overnight TA100 strains of bacterial culture. After incubation for $48 \mathrm{~h}$ at $37{ }^{\circ} \mathrm{C}$, the number of viable cells (cultured on $\mathrm{MH}$ ) and revertant colonies were determined (on minimal glucose agar) and percentage of inhibition (Index of antimutagenicity) calculated using the formula shown below. The extract was tested in triplicate and it was repeated twice. The percentage inhibition was calculated by the following formula: Percent of inhibition $(\%)=(1$

$-\mathrm{T} / \mathrm{M}) \times 100$, where $\mathrm{T}$ is the number of revertants per plate in the presence of the mutagen 4NQO, and $\mathrm{M}$ is the number of revertants per plate in the positive control (mutagen).

The mutagenic index (MI) was also calculated for each concentration tested, this being the average number of revertants per plate with the tested extract divided by the average number of revertants with the negative (solvent) control. A tested extract was considered mutagenic when a dose-response relationship was detected and a two-fold increase in the number of mutants (MI $\geq 2$ ) was observed for at least one concentration (Resende et al., 2012). 
Cell viability was also determined to assess the potential bactericidal effect of the mutagens. A substance was considered bactericidal when the bacterial survival was less than $60 \%$ of that observed in the negative control (Resende et al., 2012).

\subsection{Cytotoxic activity against Ehrlich's tumor cells in mice}

\subsubsection{Animals and experimental procedure.}

Dry extract was dissolved under sonication in water to make $5 \%(w / v)$ solution, and filtered through a $0.45 \mu \mathrm{m}$ membrane filter. The resulting solutions were kept in the refrigerator (4-8 $\left.{ }^{\circ} \mathrm{C}\right)$ until applied.

Animal care and all experimental procedures were conducted in accordance with the Guide for the Care and Use of Laboratory Animal Resources edited by the Commission of Life Sciences, National Research Council and according to approval from ethical committee for animals care at University of Novi Sad. Male and female Hannover National Medical Institute (Hann:NMRI) mice were obtained from the Biochemical Laboratory, Clinical Centre Novi Sad (Novi Sad, Serbia). Animals were fed standard mouse chow (LM2, Veterinarski zavod, Subotica, Serbia) with free access to tap water, in a temperature $\left(25^{\circ} \mathrm{C}\right)$ and humiditycontrolled (30-50\%) animal house under $12 \mathrm{~h}$ night/day cycles. NMRI mice of both sexes (6-8 weeks old) weighing $25 \pm 2.5 \mathrm{~g}$ were used in the experiments. Animals were divided into three groups of six mice under the following conditions and treatments: I, EAC group (mice with implanted EAC cells), $(n=6)$; II, mice pre-treated with the Veronica urticifolia extract, 2 $\mathrm{mg} / \mathrm{kg}$ b.w. per day, i.p., starting 7 days before the EAC implantation $(n=6)$, III, NALC group, mice pre-treated with the $N$-acetyl-L-cysteine $(5 \mathrm{mM}), 2 \mathrm{~mL} / \mathrm{kg}$ b.w. per day, i.p., starting 7 days before the EAC implantation $(n=6)$. Fourteen days after EAC implantation, all mice were killed, and the ascites of the carcinoma were collected for further experiments. 


\subsubsection{Determination of tumour cell number and cell viability.}

Ascites from the abdomen was transferred to Krebs-Ringer phosphate buffer solution $\left(0{ }^{\circ} \mathrm{C}\right.$, $\mathrm{pH}$ 7.4), then subjected to subsequential centrifuging at $4500 \mathrm{rpm}$ (MSE high speed centrifuge at $4{ }^{\circ} \mathrm{C}$ ) and $12000 \mathrm{rpm}$ (Eppendorf 3200 centrifuge, $2.5 \mathrm{~min}$ ) to obtain a dense cell suspension (1:1). The cell weight and cell number expressed as number of cells $/ \mathrm{mm}^{3}$ (counted in a Neubauer's compartment) were determined from the suspension. Cell viability was determined by the Trypan blue exclusion method: Trypan blue $(0.4 \%$ solution in KrebsRinger phosphate buffer) stained only the damaged cells. These data were expressed as percentage of damaged cells.

\subsection{Statistical analysis}

All data are presented as mean \pm standard deviations. One way analysis of variance (ANOVA) was used to detect any significant differences among different means as well as interactions between the variables used in biochemical analyses. Statistically significant effects were further analyzed and means were compared using Bonferroni test. A level of $p<0.05$ was taken as statistically significant.

\section{Results and Discussion}

\subsection{Phenolic compounds characterization}

The characterization of the phenolic compounds was performed by HPLC-DAD-ESI/MS analysis, and data of the retention time, $\lambda_{\max }$, pseudomolecular ion, main fragment ions in $\mathrm{MS}^{2}$, tentative identification and concentration of phenolic acid derivatives and flavonoids are presented in Table 1. The HPLC phenolic profile recorded at $280 \mathrm{~nm}$ can be observed in Figure 1A. 
UV and mass spectra obtained by HPLC-DAD-ESI/MS analysis showed that the phenolic composition of $V$. urticifolia was characterized by the presence of flavonoids and hydroxycinnamoyl derivatives. The analysis of the $\mathrm{MS}^{2}$ fragments revealed $O$-glycosides from two flavones (luteolin and apigenin) and hydroxycinnamoyl (caffeic acid) derivatives. Sugar substituents consisted of hexoside, deoxyhexosides, disaccharides and glucuronides, as deduced from the losses of $162 \mathrm{Da}, 146 \mathrm{Da}, 308 \mathrm{Da}$ and $176 \mathrm{Da}$, respectively.

\subsubsection{Hydroxycinnamoyl derivatives.}

These compounds correspond to caffeic (peaks 1-4, 6-8 and 10 in Table 1) or $p$-coumaric acid (peak 11) derivatives. Peak 1 was identified as 3-O-caffeoylquinic acid due to the yielded deprotonated quinic acid $(\mathrm{m} / \mathrm{z}$ at 191$)$ as base peak and another ion at $\mathrm{m} / \mathrm{z} 179$ [caffeic acid$\mathrm{H}]^{-}$, with an intensity $>50 \%$ of the base peak, a fragmentation pattern characteristic of 3acylchlorogenic acids (Clifford et al., 2005). Peaks 2 and 3 presented the same pseudomolecular ion $[\mathrm{M}-\mathrm{H}]^{-}$at $m / z 487$ and similar fragmentation pattern with the loss of 308 $\mathrm{mu}\left(\right.$ hexosyl + deoxyhexosyl moieties) yielding a base peak at $m / z 179 \mathrm{mu}\left([\text { caffeic acid-H] }]^{-}\right)$ and other two fragments at $\mathrm{m} / z 161 \mathrm{mu}\left(\left[\text { caffeic acid- } \mathrm{H}_{-}-\mathrm{H}_{2} \mathrm{O}\right]^{-}\right)$and $135 \mathrm{mu}$ ([caffeic acid-H$\left.\left.\mathrm{CO}_{2}\right]^{-}\right)$. The fact that no alternative losses of hexosyl (-162 mu) deoxyhexosyl (-146 mu) residues were observed suggested that the two sugars were constituting a disaccharide (e.g., rutinose or neohesperidose), although the actual nature of the sugar residues could not be established from the MS analysis. Thus, the compounds were tentatively assigned as as caffeoyl deoxyhexosyl-hexosides I and II.

Peak 4 corresponds to caffeic acid as identified by comparison of its UV and mass characteristics and retention time with those of the commercial standard. Peaks 6 and 8, with pseudomolecular ions [M-H] at $m / z 477$ and $m / z 453$, respectively, were attributed to caffeic 
acid derivatives, according to the observation of the characteristic peaks at $\mathrm{m} / z 179 \mathrm{mu}, 161$ mu and $135 \mathrm{mu}$, as mentioned above.

The UV spectrum of compound 7 and 10 showed the characteristic of phenylethanoid glycosides with maximum absorption peaks at 234 and $330 \mathrm{~nm}$ (Figure 1B). The HPLCDAD/ESI-MS of compound 7 in the negative mode gave $m / z 623$ as the deprotonated molecular ion $[\mathrm{M}-\mathrm{H}]^{-}$, which could be assigned to acteoside (also known as verbascoside), identity that was also supported by its UV spectrum and $\mathrm{MS}^{2}$ fragmentation pattern as reported by Li et al. (2005). Thus, $\mathrm{MS}^{2}$ of the $m / z 623$ ion ([M-H] $]^{-}$) produced a main fragment ion at $m / z 461$ considered to be from the loss of the caffeoyl moiety ([M-H-161] $)$; the weak ion at $\mathrm{m} / \mathrm{z} 315$ was consistent with the further loss of a rhamnose unit, and ions at $\mathrm{m} / \mathrm{z} 161 \mathrm{mu}$ and $135 \mathrm{mu}$ revealed the presence of the caffeoyl residue. Similar characteristics were observed for peak 10, suggesting that both compounds were isomers; they were tentatively assigned as acteoside and isoacteoside, respectively, based on their relative elution order according to Li et al. (2005). Peak 7 corresponds to the majority (14.9 $\mathrm{mg} / \mathrm{g}$ extract) phenolic compound in $V$. urticifolia extract. In fact, acteoside is a phenylethanoid glycoside, a group of phenolic compounds that is widely distributed in plants and was previously reported in Veronica species (Harput et al., 2002b; Johansen et al., 2007; Crişan et al., 2007), being inclusively considered as an important chemotaxonomic marker. The detected amounts of acteoside highlight $V$. urticifolia as a potential natural source of this bioactive compound, already reported as having antimicrobial (Avila et al., 1999), antigenotoxic (Zaabat et al., 2011) and antitumor (Ohno et al., 2002) properties.

Finally, peak 11 had a molecular ion $[\mathrm{M}-\mathrm{H}]^{-}$at $m / z 437$ that produced an $\mathrm{MS}^{2}$ base peak at $m / z 163$ ([coumaric acid-H]'), which linked to its UV spectrum $\left(\lambda_{\max }\right.$ at $\left.312 \mathrm{~nm}\right)$ allowed to assign it to an unidentified coumaric acid derivative. 


\subsubsection{Flavones.}

Flavones were the only detected flavonoids in V. urticifolia extracts (Table 1). Peaks 5 and 12 were identified as apigenin derivatives, while peaks 9 and 13 were identified as luteolin derivatives, according to their UV and mass spectra characteristics. Peaks 5 and 12 presented pseudomolecular ions [M-H] at $m / z 621$ and 445 both losing an $\mathrm{MS}^{2}$ fragment ion at $\mathrm{m} / \mathrm{z} 269$ ([M-176-176] $]^{-}$and $[\mathrm{M}-176]^{-}$, corresponding to the loss of two and one glucuronyl moieties, respectively), being tentatively identified as apigenin- $O$-diglucuronide (peak 5) and apigenin$O$-glucuronide (peak 12). The observation of the ion at $\mathrm{m} / z 445$ in peak 5 suggested that each glucuronide residue was located on different positions of the apigenin aglycone.

Peak 9 showed a pseudomolecular ion [M-H] $]^{-}$at $\mathrm{m} / z 461$ releasing an $\mathrm{MS}^{2}$ fragment ion at $\mathrm{m} / \mathrm{z}$ 285 ([M-H-176] $]^{-}$corresponding to the loss of one glucuronyl moiety) so that it could be identified as a luteolin- $O$-glucuronide. Peak 13 showed the same pseudomolecular ion $[\mathrm{M}-\mathrm{H}]^{-}$ at $m / z 461$ but it released a main fragment ion at $m / z 299$ ([M-H-162]', loss of a hexose) together with another ion at $\mathrm{m} / \mathrm{z} 285$ that might be due to the further loss of a methyl residue (-14 mu). These characteristics suggested that it could be a methyl derivative of luteolin, e.g., as chrysoeriol (3'-methyl-luteolin) or diosmetin (4'-methyl-luteolin), although its actual identity could not be established. Thus, the peak was tentatively assigned as a methyl-luteolin hexoside. Its elution order after peak 9 is also coherent with the loss of the polarity induced by the additional methyl group.

\subsection{Antibacterial activity}

The results of antibacterial activity of $V$. urticifolia methanolic extract and standard antibiotic streptomycin, tested by microdilution assay, are presented in Table 2. Staphylococcus aureus was the most sensitive species with equal values of $\mathrm{MIC}$ and $\mathrm{MBC}$ of $7.5 \mathrm{mg} / \mathrm{mL}$. The antibacterial activity of acteoside, the main phenolic compound, has already been 
demonstrated in various studies. According to Avila et al. (1999) acteoside induced lethal effect on $S$. aureus by affecting protein synthesis and inhibiting leucine incorporation. As a result of these findings, activity of $V$. urticifolia methanolic extract against $S$. aureus could be attributed at least in part to acteoside. Nevertheless, other constituents of the extract should be taken into consideration for the global activity, e.g., the high amounts of apigenin and especially luteolin glycosides.

An overwhelming body of evidence has determined the association among certain bacteria and cancer (Mager, 2006). Bacteria have been linked to cancer by two mechanisms: induction of chronic inflammation and production of carcinogenesis. The staphylococcal $\alpha$-toxin has been shown to activate both several cytokines which have been linked to all steps in tumor development and nuclear factor $\kappa \mathrm{B}$, known tumor promoter in the development of hepatocellular carcinoma (Kullander et al., 2009).

Micrococcus flavus, Listeria monocytogenes and Enterococcus faecalis were similarly susceptible to the inhibitory ( $\mathrm{MIC}=7.5 \mathrm{mg} / \mathrm{mL})$ and bactericidal $(\mathrm{MBC}=15 \mathrm{mg} / \mathrm{mL})$ effects of the extract. The most resistant species were Bacillus cereus, Pseudomonas aeruginosa and Escherichia coli with $\mathrm{MIC}=\mathrm{MBC}=15 \mathrm{mg} / \mathrm{mL}$. As shown in Table 2, streptomycin has stronger activity than tested extract. The obtained results for antibacterial activity are comparable to those published previously for $V$. montana water extract (Stojkovic et al., 2013).

\subsection{Antimutagenicity testing}

As mutations are known to be the most important cause of the initiation of many diseases, phytochemicals exhibiting antimutagenic potential could be of immense significance (Kumar et al., 2013). It has been suggested that the use of antimutagen in daily life will be the most effective procedure for preventing human cancer and genetic disease (Bhagavathy et al., 
2011). Antimutagenic compounds (e.g. carotenoids) interfere with mutagen metabolism, they may act as mutagen scavengers, or they may also inhibit either the initiation or promotion phase of the carcinogenic process (Bhagavathy et al., 2011). Although an antimutagenic effect found in a plant extract does not necessarily mean that it is an anticarcinogen, it is however an indication of the possibility of acting as one (Abdillahi et al., 2012). The Ames Salmonella test is widely accepted short-term bacterial assay for identifying substances that can produce genetic damage that leads to gene mutations. The test uses Salmonella strains with preexisting mutations that leave the bacteria unable to synthesize the required amino acid, histidine, and therefore unable to grow and form colonies in its absence. New mutations at the site of these pre-existing mutations, or nearby in the genes, can restore the gene's function and allow the cells to synthesize histidine. These newly mutated cells can grow in the absence of histidine and form colonies (Mortelmans and Zeiger, 2000).

Lesions to DNA resulting from attack by reactive oxygen species (ROS) can be a major cause of mutagenesis and carcinogenesis (Mimica-Dukić et al., 2010). Therefore, antioxidants may act as universal antimutagenic agents (Ananthi et al., 2010). In a previous research, we demonstrated the protective role of methanolic extract of $V$. urticifolia in oxidative stress helping to keep normal levels of enzymatic and non-enzymatic antioxidants and lipid peroxidation (Živković et al., 2012). Based on this, we extent our evaluation using the Ames Salmonella test.

In this study, the mutagenicity of $V$. urticifolia methanolic extract against $S$. typhimurium TA 100 was measured by comparing the ratio of induced revertants and spontaneous revertants in plates. According to Table 3, the mutagenicity index showed that tested extract in the range $0.2-1 \mathrm{mg} / \mathrm{plate}$, did not induce increase in the number of revertant colonies relative to the negative control, indicating the absence of any mutagenic activity. 
As reported in Table 3, tested extract displayed protective effects against 4-NQO induced mutagenicity. In determining the antimutagenic potential of a sample, a value smaller than $25 \%$ inhibition of the mutagen activity indicates a weak or non-antimutagenic effect, a moderate effect when the value is between 25 and $40 \%$ and strong antimutagenicity when the value is greater than $40 \%$ (Negi et al., 2003). In the present study induced inhibition was dose dependent: $0.2 \mathrm{mg} /$ plate and $0.5 \mathrm{mg} /$ plate induced moderate antimutagenic activity reducing histidine-prototrophic revertant colonies by $25.8 \%$ and $36.2 \%$, respectively. At $1 \mathrm{mg} / \mathrm{plate}$ the extract showed strong inhibitory effect against direct-acting mutagen 4NQO (inhibition rate was $48.3 \%$ ). Since the extract plus bacterial strain treated plate did not produce any change in the background growth of bacteria with respect to the plate used to detect the spontaneous revertant, the antimutagenic activity of extract cannot be correlated to its toxicity to bacterial strains.

The exhibited antimutagenic activity of the extract might be ascribed to its constituents, in particular to the major phenolic compounds (acteoside and luteolin- $O$-glucuronide) polyphenols. In fact, some phenylpropanoids act as potent antimutagenic and anticarcinogenic agents (Miyazawa and Hisama, 2003). According to Zaabat et al. (2011) acteoside showed pronounced antigenotoxic effect. Therefore, taking into consideration the concentration of acteoside in the extract, it can be suggested that acteoside could be an essential compound for the antimutagenic activity of $V$. urticifolia.

Keeping in prospect our previous publication regarding the antioxidant activity of tested extract, the exhibited antimutagenic activity might also be partially ascribed to its antioxidant activity.

\subsection{Cytotoxic activity against Ehrlich's tumor cells in mice}


Plants belonging to the genus Veronica and several of their constituents have shown potent cytotoxic activity on different cell lines (Harput et al., 2002a; Teng et al., 2008; Saracoglu and Harput, 2012). In the present study the $V$. urticifolia methanolic extract was evaluated for its in vivo antitumor properties.

The Ehrlich tumor was initially described as a spontaneous murine mammary adenocarcinoma. It is a rapidly growing carcinoma with very aggressive behaviour. After intraperitoneal inoculation of Ehrlich tumor cells, the ascitic volume and cells number increase drastically. This has been associated to an increase in peritoneal vascular permeability (De Matos Gomes et al., 2008). In clinical situations, formation of ascites is often observed in patients with advanced cancer.

The involvement of free radicals in tumors is well documented. Previous investigations showed that EAC-bearing mice are under higher oxidative stress than control animals indicated by elevated lipid and protein oxidation and reduced endogenous antioxidants in the liver (Al Abdan, 2012). If oxidative stress is involved in the origin of EAC-induced oxidative injury, then a successful antioxidant treatment should protect against that injury. To test the hypothesis that tumor cell growth is based on the change in antioxidant status in EAC cells $N$ acetyl-L-cysteine, a thiol antioxidant precursor of glutathione (NALC) is used as a positive control in investigation.

Antitumor properties of $V$. urticifolia methanolic extract were assessed by parameters such as ascites volume, tumor cell count and cell viability; the results are shown in Table 4. A single dose of tested extract was chosen since the preliminary results using different doses $(0.2 ; 0.5$; $1.0 ; 1.5$ and $2.0 \mathrm{~mL} / \mathrm{kg} \mathrm{b.w.)} \mathrm{indicated} \mathrm{that} 2.0 \mathrm{mg} / \mathrm{kg} \mathrm{b.w}$. was the most effective dose. For the purpose of preliminary elucidation i.p. administration of the extract prior to oral application was chosen, in order to avoid possible chemical changes upon oral consumption of the extract. 
The Ehrlich ascitic tumor implantation induces per se a local inflammatory reaction, with increasing vascular permeability, which results in an intense edema formation, cellular migration and progressive ascitic fluid formation (Agrawal et al., 2011). The ascitic fluid is essential for tumor growth, since it constitutes a direct nutritional source for tumor cells (De Matos Gomes et al., 2008). Our data showed that administration of NALC significantly reduced the ascitic fluid volume. On the other hand, after application of $V$. urticifolia methanolic extract the ascites volume became slightly decreased, but not to a statistically significant extent.

Ascites fluid accumulation occurs in parallel with the proliferation of tumor cells (Ozaslan et al., 2011). Cytotoxic activity can be determined as a decreased-cell number because of cell death, while cell-growth inhibitory or cytostatic activity can be determined as a suppression of the increase of cell number without causing cell death. Administration of NALC or investigated extract during the course of this experiment led to slight, but insignificant reduction of number of tumor cells in peritoneal cavity as compared to control group, pointing to their oncostatic activity.

Prolongation of survival is directly related to decrease in viable cell count (Agrawal et al., 2011). In the present study a significantly decreased EAC cell viability after administration of the tested extract in comparison to the control group was observed. Administration of the NALC showed no effect on tumor cell viability.

In conclusion, the observed antibacterial, antimutagenic and oncostatic effects of $V$. urticifolia methanol extract indicates that this species may play a role as a cancer-preventing agent. The effect can be partially ascribed to the phenolic compounds identified in the extract. Nevertheless, further studies are needed to explain the role of phytochemicals in the bioactivities of $V$. urticifolia. 


\section{Acknowledgements}

The authors acknowledge their gratitude to the Ministry of Education, Science and Technological Development of Serbia for financial support, project number 173015.

The authors are grateful to Fundação para a Ciência e a Tecnologia (FCT, Portugal) for financial support to CIMO (strategic project PEst-OE/AGR/UI0690/2011). J.C.M. Barreira thanks FCT, POPH-QREN and FSE for his grant (SFRH/BPD/72802/2010). The GIP-USAL is financially supported by the Spanish Government through the Consolider-Ingenio 2010 Programme (FUN-C-FOOD, CSD2007-00063) and project ref. BFU2012-35228. 


\section{References}

Abdillahi, H. S., Verschaeve, L., Van Staden, J. (2012). Mutagenicity, antimutagenicity and cytotoxicity evaluation of South African Podocarpus species. Journal of Ethnopharmacology, 139, 728-738.

Agrawal, S. S., Saraswati, S., Mathur, R., Pandey, M. (2011). Antitumor properties of Boswellic acid against Ehrlich ascites cells bearing mouse. Food and Chemical Toxicology, 49, 1924-1934.

Al Abdan, M. (2012). Alfa-lipoic acid controls tumor growth and modulates hepatic redox state in Ehrlich-ascites-carcinoma-bearing mice. The Scientific World Journal. 2012, Article ID. 509838, 1-6.

Albach, D. C., Grayer, R. J., Jensen, S. R., Özgökce, F., Veitch, N. C. (2003). Acylated flavone glycosides from Veronica. Phytochemistry, 64, 1295-1301.

Albach, D. C., Grayer, R. J., Kite, G. C., Jensen, S. R. (2005). Veronica: Acylated flavone glycosides as chemosystematic markers. Biochemical Systematics and Ecology, 33, $1167-1177$.

Ananthi, R., Chandra, N., Santhiya, S. T., Ramesh, A. (2010). Genotoxic and antigenotoxic effects of Hemidesmus indicus R. Br. root extract in cultured lymphocytes. Journal of Ethnopharmacology, 127, 558-560.

Assaf, A. M., Haddadin, R. N., Aldouri, N. A., Alabbassi, R., Mashallah, S., Mohammad, M., Bustanji, Y. (2013). Anti-cancer, anti-inflammatory and anti-microbial activities of plant extracts used against hematological tumors in traditional medicine of Jordan. Journal of Ethnopharmacology, 145, 728-736. 
Avila, J. G., De Liverant, J. G., Martinez, A., Martinez, G., Muñoz, J. L., Arciniegas, A., De Vivar, A. R. (1999). Mode of action of Buddleja cordata verbascoside against Staphylococcus aureus. Journal of Ethnopharmacology, 66, 75-78.

Bhagavathy, S., Sumathi, P., Madhushree, M. (2011). Antimutagenic assay of carotenoids from green algae Chlorococcum humicola using Salmonella typhimurium TA98, TA100 and TA102. Asian Pacific Journal of Tropical Disease, 1, 308-316.

Clifford, M. N., Knight, S., Kuhnert, N. A. (2005). Discriminating between the six isomers of dicaffeoylquinic acid by LC-MS ${ }^{\mathrm{n}}$. Journal of Agricultural and Food Chemistry, 53, 3821-3832.

Crişan, G., Tămaş, M., Miclăuş, V., Krausz, T., Sandor, V. (2007). A comparative study of some Veronica species. Revista Medico-Chirurgicala a Societatii de Medici si Naturalisati Iasi, 111, 280-284.

De Flora, S. (1998). Mechanisms of inhibition of mutagenesis and carcinogenesis. Mutation Research, 402, 151-158.

De Matos Gomes, N., De Moraes Rezende, C., Fontes, S. P., Hovell, A. M., Landgraf, R. G., Matheus, M. E., Pinto Ada, C., Fernandes, P. D. (2008). Antineoplasic activity of Copaifera multijuga oil and fractions against ascitic and solid Ehrlich tumor. Journal of Ethnopharmacology, 119, 179-184.

Dhamija, I., Kumar, N., Manjula, S. N., Parihar, V., Setty, M. M., Pai, K. S. R. (2013). Preliminary evaluation of in vitro cytotoxicity and in vivo antitumor activity of Premna herbacea Roxb. in Ehrlich ascites carcinoma model and Dalton's lymphoma ascites model. Experimental and Toxicologic Pathology, 65, 235-242. 
El-Sayed, W. M., Hussin, W. A. (2013). Antimutagenic and antioxidant activity of novel 4-substituted phenyl-2,2'-bichalcophenes and aza-analogs. Journal of Drug Design, Development and Therapy, 7, 73-81.

Espinel-Ingroff, A. (2001). Comparation of the E-test with the NCCLS M38-P method for antifungal susceptibility testing of common and emerging pathogenic filamentous fungi. Journal of Clinical Microbiology, 39, 1360-1367.

Gusev, N. F., Nemereshina, O. N., Petrova, G. V., Sychev, M. V. (2012). Evaluation of antibacterial activity and biologically active substances of herbal drugs from Veronica L. Russian Journal of Biopharmaceuticals, 4, 17-22.

Harput, U. S., Saracoglu, I., Inoue, M., Ogihara, I. (2002a). Anti-inflammatory and cytotoxic activities of five Veronica species. Biological and Pharmaceutical Bulletin, 25, 483-486.

Harput, U. S., Saracoglu, I., Inoue, M., Ogihara, I. (2002b). Phenylethanoid and iridoid glycosides from Veronica persica. Chemical and Pharmaceutical Bulletin, 50, $869-871$.

IUPAC (1976). Nomenclature of cyclitols. Biochemical Journal, 153, 23-31.

Johansen, M., Larsen, T. S., Mattebjerg, M. A., Gotfredsen, C. H., Jensen, S. R. (2007). Chemical markers in Veronica sect. Hebe. Biochemical Systematic and Ecology, 35, 614-620.

Kullander, J., Forslund, O., Dillner, J. (2009). Staphylococcus aureus and squamous cell carcinoma of the skin. Cancer Epidemiology, Biomarkers and Prevention, 18, 472-478. 
Kumar, S., Gautam, S., Sharma, A. (2013). Identification of antimutagenic properties of anthocyanins and other polyphenols from rose (Rosa centififolia) petals and tea. Journal of Food Science, 78, H948-H954.

Li, L., Tsao, R., Liu, Z., Liu, S., Yang, R., Young, J. C., Zhu, H., Deng, Z., Xie, M., Fu, Z. (2005). Isolation and purification of acteoside and isoacteoside from Plantago psyllium L. by high-speed counter-current chromatography. Journal of Chromatography A, 1063, 161-169.

Madhusudan, S., Middleton, M. R. (2005). The emerging role of DNA repair proteins as predictive, prognostic and therapeutic targets in cancer. Cancer Treatment Reviews, 31, 603-617.

Mager, D.L. (2006). Bacteria and cancer: cause, coincidence or cure? A review. Journal of Translation Medicine, 4, article No. 14.

Martin, M. A. , Goya, L., Ramos, S. (2013). Potential for preventive effects of cocoa and cocoa polyphenols in cancer. Food and Chemical Toxicology, 56, 336-351.

Mignogna, M. D., Fedele, S., Lo Russo, L. (2004). The World Cancer Report and the burden of oral cancer. European Journal of Cancer Prevention, 13, 139-142.

Mimica-Dukić, N., Bugarin, D., Grbović, S., Mitić-Ćulafić, D., Vuković-Gačić, B., Orčić, D., Jovin, E., Couladis, M. (2010). Essential oil of Myrtus communis L. as a potential antioxidant and antimutagenic agents. Molecules, 15, 2759-2770.

Miyazawa, M., Hisama, M. (2003). Antimutagenic activity of phenylpropanoids from clove (Syzygium aromaticum). Journal of Agricultural and Food Chemistry, 51, 6413-6422. 
Mortelmans, K., Zeiger, E. (2000). The Ames Salmonella/microsome mutagenicity assay. Mutation Research, 455, 29-60.

Negi, P. S., Jayaprakasha, G. K., Jena, B. S. (2003). Antioxidant and antimutagenic activities of pomegranate peel extracts. Food Chemistry, 80, 393-397.

Ohno, T., Inoue, M., Ogihara, Y., Saracoglu, I. (2002). Antimetastatic activity of acteoside, a phenylethanoid glycoside. Biological and Pharmaceutical Bulletin, 25, 666-668.

Ozaslan, M., Karagoz, I. D., Kilic, I. H., Guldur, M. E. (2011). Ehrlich ascites carcinoma. African Journal of Biotechnology, 10, 2375-2378.

Resende, F. A., Barbosa, L. C., Tovares, D. C., De Camargo, M. S., De Souza Rezende, K. C., De Silva, M. L. D. A., Varanda, E. A. (2012). Mutagenicity and antimutagenicity of (-)-hinokinin a trypanosomicidal compound measured by Salmonella microsome and comet assays. BMC Complementary and Alternative Medicine, 12, article No. 203.

Saracoglu, I., Varel, M., Harput, S., Nagatsu, A. (2004). Acylated flavonoids and phenol glycosides from Veronica thymoides subsp. pseudocinera. Phytochemistry, 65, $2379-2385$.

Saracoglu, I., Harput, U. S. (2012). In vitro cytotoxic activity and structure activity relationships of iridoid glucosides derived from Veronica species. Phytotherapy Research, 26, 148-152.

Shi, Y., Wu, C., Chen, Y., Liu, W., Feng, F., Xie, N. (2013). Comparative analysis of three Callicarpa herbs using high performance liquid chromatography with diode 
array detector and electrospray ionization-trap mass spectrometry method. Journal of Pharmaceutical and Biomedical Analysis 75, 239-247.

Stojković, D. S., Živković, J., Soković, M., Glamočlija, J., Ferreira, I. C. F. R., Janković, T., Maksimović, Z. (2013). Antibacterial activity of Veronica montana L. extract and of protocatechuic acid incorporated in a food system. Food and Chemical Toxicology, 55, 209-213.

Taskova, R. M., Gotfredsen, C. H., Jensen, S.R. (2006). Chemotaxonomy of Veroniceae and its allies in the Plantaginaceae. Phytochemistry, 67, 286-301.

Taskova, R. M., Kokubun, T., Grayer, R. J., Ryan, K. G., Garnock-Jones, P. J. (2008). Flavonoid profiles in the Heliohebe group of New Zealand Veronica (Plantaginaceae). Biochemical Systematic and Ecology, 36, 110-116.

Teng, J., Li, H. Q., Yao, Z., Zhang, Y. W., Zhang, F. G., Duan, H. Q., 2008. Anticancer activity of diterpenes from Veronica sibirica in vitro. Zhong Cao Yao, 39, 967970.

Zaabat, N., Hay, A. E., Michalet, S., Darbour, N., Bayet, C., Skandrani, I., ChekirGhedira, L., Akkal, S., Dijoux-Franca, M. G. (2011). Antioxidant and antigenotoxic properties of compounds isolated from Marrubium deserti de Noé. Food and Chemical Toxicology, 49, 3328-3335.

Živković, J., Ćebović, T., Maksimović, Z. (2012). In vivo and in vitro antioxidant effects of three Veronica species. Central European Journal of Biology, 7, 559-568. 


\section{FIGURE CAPTION}

Figure 1. HPLC chromatogram (the period from 5.5 to 6.1 minutes was zoomed to elucidate peaks 1, 2 and 3) of the phenolic compounds of Veronica urticifolia recorded at $280 \mathrm{~nm}(\mathbf{A})$. The UV spectrum of the dominant compound (acteoside) is also shown (B). 